\title{
Bingkai Halal dan Non Halal: Studi Kasus Penerapan Halal Food di Restoran Spice Beach Club Bali
}

\author{
Zein Faraudis, Nyoman Dini Andiani, Putu Indah Rahmawati \\ Prodi Perhotelan, Jurusan Manajemen, Fakultas Ekonomi, Universitas Pendidikan Ganesha, \\ Singaraja.
}

\begin{abstract}
Abstrak
Penelitian ini bertujuan untuk mengetahui proses penyimpanan bahan halal dan nonhalal di Spice Beach Club Bali serta mengetahui eksistensi hidangan halal di Spice Beach Club Bali. Penelitian ini adalah penelitian desktiptif kualitatif. Hasil penelitian ini menunjukan bahwa, 1) Dalam penyimpanan bahan halal dan non halal dilakukan dalam satu tempat dan setiap bahan akan dijadikan satu wadah menurut jenis dan kategori bahan tersebut, 2) Eksistensi hidangan halal di Spice Beach Club Bali disukai oleh para tamu. Ini bisa dilihat dari pemesanan terhadap hidangan halal sekitar $91,7 \%$. Jika dilihat, sebagian besar menu makanan dari Spice Beach Club Bali merupakan hidangan halal.

Kata Kunci : Penyimpanan, Halal, Non-Halal dan Eksistemsi.
\end{abstract}

Abstract

This study aims to find out how to store halal and nonhalal ingredients at Spice Beach Club Bali and also to find out the existence of halal dishes at Spice Beach Club Bali. This research is a qualitative descriptive study. This research is a qualitative descriptive study. These results indicate that 1) in storing halal and nonhalal ingredient in one place and each ingredient will be made into one container according to the type and category of said ingredient, 2) approximately $91,7 \%$ restaurant customer order halal dishes. Most food menus from the Spice Beach Club Bali are halal dishes.

Keywords : Storage, Halal, Non-Halal and Existence.

\section{Pendahuluan}

Makanan dan minuman tercatat sebagai salah satu bisnis dengan potensi yang akan terus meningkat, dikarenakan makanan dan minuman merupakan kebutuhan pokok umat manusia. Salah satu usaha yang sedang berkembang saat ini adalah restoran. Restoran merupakan tempat menyajikan hidangan kepada tamu dan menyediakan tempat untuk menikmati hidangan tersebut dan menetapkan harga terhadap hidangan tersebut. Terdapat beberapa tipe restoran yaitu, restoran yang menghidangkan makanan dengan bahan halal dan restoran yang menghidangkan makanan dengan bahan nonhalal. Makanan halal merupakan makanan dengan bahan yang digunakan halal. 
Salah satu restoran yang mempunyai hidangan halal dan nonhalal yaitu Spice Beach Club Bali. Spice Beach Club Bali merupakan restoran bintang empat yang berada di daerah Bali Utara yang menjadikan restoran ini menjadi yang terbaik di daerah Bali Utara. Menu makanan yang ada di Spice Beach Club Bali terdiri dari dua kategori yaitu halal dan nonhalal. Rasa khawatir pelanggan yang tidak boleh mengkonsumsi makanan tidak halal bukan hanya dari proses pembuatannya saja melainkan juga dari bagaimana penyimpanan dua bahan ini yaitu bahan halal dan nonhalal. Pelaksanaan penyimpanan kedua bahan ini tidak dilakukan secara sembarangan. Penyimpanan dilakukan dalam satu tempat tapi, dalam pengemasan atau mewadahkan bahan-bahan ini disesuaikan dengan jenis bahan, kategori bahan dan kriteria bahan tersebut. Sehingga bahan makanan halal dan nonhalal tidak akan mengalami sentuhan secara langsung. Tujuan lain dari dilaksanakan pengemasan atau mewadahkan ini adalah untuk mempermudah pada saat pengambilan bahan makanan di tempat penyimpanan seperti freezer atau kulkas.

Pengetahuan restoran yang memiliki hidangan halal dan nonhalal saat ini masih kurang, karena menganggap makanan halal itu hanya dari bahannya saja. Terdapat beberapa faktor yang membuat makanan halal menjadi nonhalal seperti, dicampurkannya bahan red wine vinegar, red wine dan white wine. Berdasarkan latar belakang masalah di atas maka perlu diteliti lebih lanjut mengenai "Penerapan Halal Pada Makanan di Restoran Spice Beach Club Bali”. Dari uraian latar belakang diatas, maka penelitian ini bertujuan untuk mendeskripsikan cara penyimpanan bahan halal dan nonhalal di Spice Beach Club Bali serta mengetahui eksistensi hidangan halal di Spice Beach Club Bali.

\section{Kajian Pustaka}

Peneletian mengenai halal pada makanan banyak dilakukan oleh peneliti sebelumnya sehingga dapat dilakukannya pembahasan dalam penelitian ini. Beberapa penelitian yang dapat mendukung penelitian ini, diantaranya : Zulaekah \& Kusumawati (2005) menyatakan, Penentuan status halal suatu makanan atau bahan makanan tambahan yang diproses, umat Islam harus melihat atau mencari tahu dengan pasti sumber bahan apakah dari hewan atau tumbuhan.

Seperti yang diungkapkan Bahruddin (2010) bahwa diperlukan kewaspadaan yang tinggi terhadap produk hewani dari aspek kehalalanya dikarenakan masih minimnya kalangan produsen untuk mengurus sertifikasi jaminan produk halal. Salehudin \& Mukhlish (2012) 
menyatakan, Pemasaran halal merupakan konsep yang penting bagi pemasar yang ingin berbisnis di negara dengan mayoritas penduduk Muslim seperti Indonesia. Achyar (2014) juga mengungkapkan permintaan produk halal, baik itu makanan, minuman, maupun wisata halal semakin meningkat. Rama (2014) menyatakan, Potensi produk halal pada hakekatnya tidak hanya untuk negara-negara Muslim saja atau penduduk Muslim saja tetapi juga bagi para konsumen yang memiliki preferensi terhadap makanan yang sehat dan berkualitas. Adapun beberapa konsep yang bisa dijadikan acuan dalam membahas masalah dalam penelitian ini, sebagai berikut :

\subsection{Konsep Restoran dan Faktor-faktor yang Mempengaruhinya}

Menurut Rutherford dan O'Fallon (2010), Restaurant adalah fasilitas yang menyajikan berbagai jenis makanan dan minuman untuk para tamu, yang dirancang untuk kenyamanan para tamu dalam menikmati hidangan. Pengadaan makanan halal di setiap restoran merupakan sesuatu yang harus dilakukan jika ingin menjangkau seluruh konsumen. Untuk itu, diperlukan strategi yang dapat menjangkau seluruh konsumen. Menurut Salusu (2006:101), Strategi yaitu suatu seni menggunakan kecakapan dan sumber daya suatu organisasi untuk mencapai sasarannya melalui hubungan yang efektif dengan lingkungan dalam kondisi yang paling menguntungkan. Industri makanan halal akan terus meningkat hal ini disebabkan karena banyak konsumen yang memiliki preferensi tehadap makanan yang sehat dan berkualitas. Makanan halal otomatis sehat dan berkualitas. Sebaliknya, makanan yang berkualitas belum tentu halal. Dengan demikian preferensi makanan halal tidak dibatasi oleh agama tertentu tetapi berlaku bagi setiap konsumen yang peduli terhadap kualitas dan proses suatu produk.

\subsection{Konsep Makanan Halal di Restoran}

Produk makanan atau pangan adalah segala sesuatu yang berasal dari sumber hayati atau air, baik yang diolah maupun tidak diolah, yang diperuntukkan untuk makanan atau minuman bagi konsumsi manusia (Saparinto \& Hidayati, 2010). Makanan dikatakan halal apabila, 1) Bukan terdiri atau mengandung bahan-bahan dari binatang yang tidak diperbolehkan untuk dikonsumsi atau tidak disembelih menurut ketentuan ajaran Islam, 2) Tidak mengandung bahan-bahan yang berasal dari binatang yang najis. Seperti binatang anjing, 3) Tidak disiapkan atau diproses menggunakan bahan-bahan atau peralatan yang tidak terbebas dari najis dan haram, 4) Dalam proses pengadaan, pengolahan dan penyimpanannya, tidak bersentuhan atau berdekatan dengan bahan-bahan yang tidak memenuhi point a,b dan c. 


\subsection{Konsep Proses Pengolahan dan Penyimpanan Bahan Makanan}

Dalam pelaksanaanya, terdapat banyak hal yang mempengaruhi suatu bahan makanan bisa dikatakan nonhalal meskipun bahan itu berasal dari bahan yang halal, salah satunya proses dalam menyembelih binatang. Dalam proses menyembelih, jika tidak mengetahui ketentuan dalam pelaksanaannya maka binatang yang halal tersebut bisa menjadi nonhalal. Berikut cara bagaimana menyembelih binatang sesuai ketentuan yang benar (Bahruddin, 2010), diantaranya : 1) Penyembelihan harus dilakukan oleh orang yang sempurna akalnya, mengetahui syarat-syarat penyembelihan, tidak boleh oleh anak-anak atau orang gila, 2) Binatang yang disembelih haruslah binatang yang halal dimakan, 3) Ketika disembelih binatang tersebut masih hidup, 4) Membaca "Bismillahi" ketika menyembelih setiap binatang, 5) Sembelihan harus menggunakan alat yang tajam dan memutuskan kedua urat leher saluran pernafasan dan saluran makanan / minuman, 6) Sembelihan dilakukan satu kali putus, dalam artian ketika menyembelih tidak boleh mengangkat pisau sebelum kedua urat lahernya putus. Pada saat memasak, penambahan bahan seperti wine akan membuat masakan tersebut menjadi lebih nikmat tapi, dalam makanan halal penambahan alkohol seperti wine dan sebagainya membuat makanan tersebut manjadi nonhalal. Dikarenakan, alkohol atau minuman yang memabukkan merupakan barang nonhalal.

\section{Metodelogi Penelitian}

Penelitian ini dilaksanakan selama enam bulan di restoran Spice Beach Club Bali yang beralamat di Pantai Lovina, JI. Seririt-Singaraja No. 225, Kaliasem, Banjar, Kabupaten Buleleng. Lokasi diatas dipilih dikarenakan sebagian hidangan menggunakan bahan halal dan sebagiannya lagi tidak. Dalam pelaksanaan penelitian ini, menghasilkan data berupa proses penyimpanan bahan halal dan nonhalal di restoran Spice Beach Club Bali. Dengan sumber data primer dan sekunder dan juga melalui beberapa teknik pengumpulan data seperti wawancara, observasi langsung dilapangan dan juga melakukan dokumentasi. Subjek dalam penelitian ini adalah chef Spice Beach Club Bali dan staff kitchen yang dapat memberikan data terkait. Yang menjadi objek dalam peneletian ini adalah proses penyimpanan bahan halal dan nonhalal di restoran Spice Beach Club Bali. Teknik analisis data yang digunakan adalah analisis data deskriptif kualitatif. Winartha (2006:155) metode analisis deskriptif kualitatif adalah menganalisis, menggambarkan dan meringkas berbagai kondisi. 


\subsection{Cara Penyimpanan Bahan Halal dan Bukan Halal di Spice Beach Club}

Menurut keterangan salah satu staff Spice Beach Club Bali, dalam penyimpanan bahan halal dan nonhalal dilakukan dalam satu tempat dan setiap bahan akan dijadikan satu wadah menurut jenis dan kategori bahan tersebut. Selain untuk menjaga bahan makanan agar tidak bersentuhan secara langsung, juga bertujuan untuk mempertahankan usia bahan makanan sehingga dapat sampai ke tangan konsumen atau pelanggan dalam keadaan masih segar atau layak. Seperti mince beef dan pork chop, kedua bahan ini dalam penyimpanannya ditempatkan dalam satu tempat dengan wadah yang berbeda, hal ini dilakukan agar mince beef tidak terkontaminasi atau bersentuhan secara langsung oleh pork chop yang berjenis bahan nonhalal. Setiap bahan makanan yang ada di Spice Beach Club Bali memiliki wadah tersendiri menggunakan kantong plastik, hal ini bertujuan untuk mengkelompokkan setiap bahan makanan dan juga untuk kemudahan dalam pengambilan bahan makanan.

Adanya wadah atau pembungkus dapat membantu mencegah atau mengurangi kerusakan, melindungi bahan makanan yang ada di dalamnya dan melindungi dari bahaya pencemaran. Plastik merupakan salah satu jenis bahan kemas yang paling sering digunakan selain bahan kemas yang lain. Plastik, bahan pengemasan yang mudah di dapatkan dan fleksibel penggunaanya. Selain untuk mengemas barang bukan pangan, plastik juga dapat digunakan langsung untuk mengemas bahan makanan. Setiap bahan makanan yang ada di Spice Beach Club Bali memiliki wadah tersendiri menggunakan kantong plastik, hal ini bertujuan untuk mengelompokan setiap bahan makanan dan juga untuk kemudahan dalam pengambilan bahan makanan.
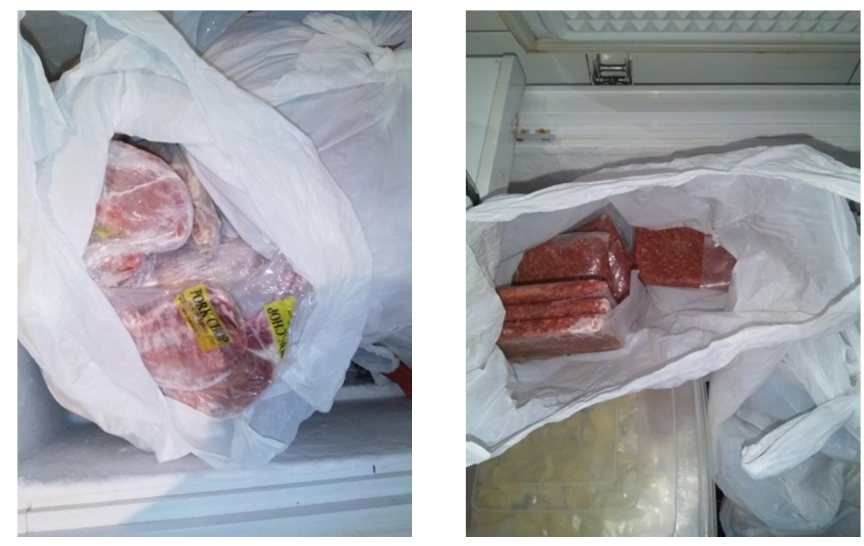

Sumber : Dokumentasi Penulis 2019 
Gambar diatas menjelaskan bahwa penyimpanan bahan makanan di Spice Beach Club Bali dilakukan dalam satu tempat dengan wadah yang berbeda. Meskipun terdapat bahan makanan nonhalal, akan tetapi pemberian wadah ini bertujuan agar bahan makanan yang halal tidak bersentuhan secara langsung dengan bahan makanan nonhalal.

\subsection{Eksistensi Hidangan Halal di Spice Beach Club}

Dari hasil wawancara dengan salah satu staff Spice Beach Club Bali, eksistensi hidangan halal di Spice Beach Club Bali disukai oleh para tamu. Ini bisa dilihat dari pemesanan makanan pada bulan Mei 2019 terhadap hidangan halal sekitar 91,7\%. Jika dilihat, sebagian besar menu makanan dari Spice Beach Club Bali merupakan hidangan halal. Seperti Nasi Goreng, Mi Goreng, Rendang Sapi, Mega Beef Burger, Sumatra Duck Leg Curry, Madurese Chicken Sate, Grilled Lobster, Salmon Steak, Grilled Seafood Platter, Pumkin Soup, Garam Asam, Lumpia Semarang dan lainnya.
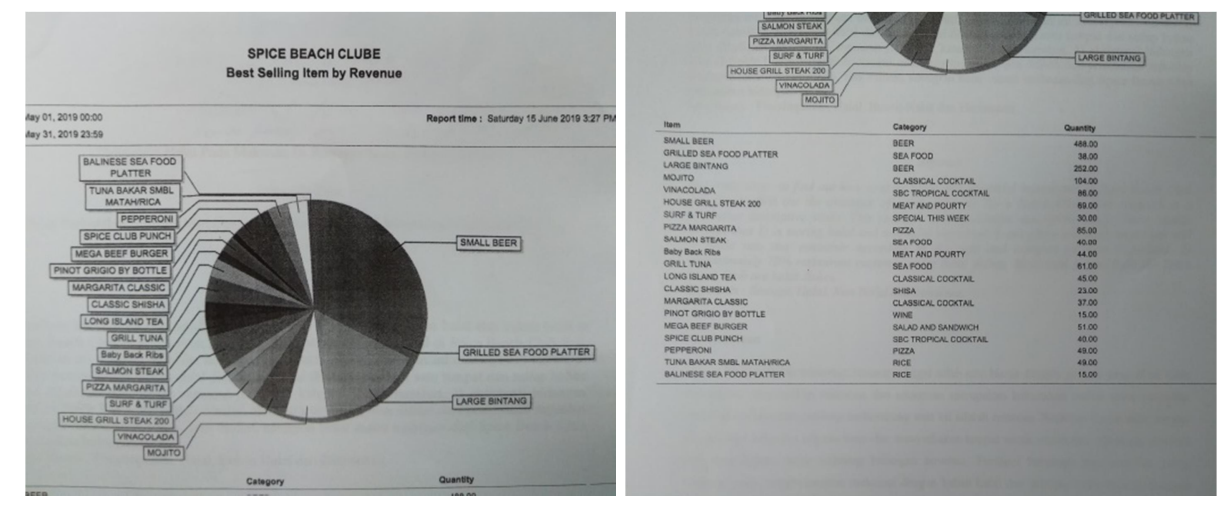

Sumber : Dokumentasi Penulis 2019

Data diatas menjelaskan pemesanan makanan pada bulan Mei 2019 terhadap hidangan halal sebesar $91,7 \%$. Potensi produk halal pada hakekatnya tidak hanya untuk negara-negara Muslim saja atau penduduk Muslim saja tetapi juga bagi para konsumen yang memiliki preferensi terhadap makanan yang sehat dan berkualitas. Makanann halal otomatis sehat dan berkualitas. Sebaliknya, makanan yang berkualitas belum tentu halal.

Dari fakta diatas antusias tamu terhadap makanan halal cukup tinggi. Dari pengamatan secara langsung, terdapat beberapa makanan nonhalal jika dihilangkan beberapa bahannya akan menjadi makanan halal, seperti Fettuccine Carbonara dan Fettuccine Seafood. Dua hidangan ini mempunyai bahan dasar nonhalal seperti bacon pada Fettuccine Carbonara dan white wine pada Fettuccine Seafood. Jika bacon dihilangkan atau diganti dengan smoked beef maka hidangan Fettuccine Carbonara tersebut menjadi halal, hal serupa terjadi jika white wine 
pada Fettuccine Seafood tidak digunakan maka Fettuccine Seafood tersebut akan menjadi halal. Pada era saat ini, modifikasi makanan merupakan kejadian yang sering terjadi karena chef dan pihak restoran mencoba untuk menyesuaikan dengan cita rasa sekitar.

Berdasarkan pengamatan yang dilakukan secara langsung melalui proses wawancara dengan salah satu staff Spice Beach Club Bali. Maka dapat dilihat eksistensi hidangan halal di Spice Beach Club Bali mendapat sambutan yang baik dari para tamu. Hasil ini menunjukkan bahwa, potensi produk halal untuk saat ini akan terus meningkat. Data tersebut menjelaskan pasar makanan halal akan terus meningkat setiap tahunnya dan akan selalu diminati oleh semua masyarakat umum baik itu Muslim maupun bukan Muslim.

\section{Simpulan}

Berdasarkan penelitian yang dilakukan melalui pengamatan langsung di lapangan, wawancara dan pembahasan yang telah diuraikan pada bab sebelumnya, maka dari penerapan halal pada makanan di Spice Beach Club Bali dapat disimpulkan sebagai berikut: 1) Prosedur penyimpanan bahan halal dan bukan halal di Spice Beach Club Bali sudah sesuai dengan ketentuan, hal itu bisa dilihat dari bagaimana staff kitchen mengelompokkan setiap bahan sesuai dengan jenisnya dan mewadahkan setiap bahan menggunakan kantong plastik agar tidak bersentuhan secara langsung. 2) Hidangan halal mendapatkan sambutan yang baik oleh para tamu, tidak sedikit tamu yang menyukai hidangan halal di Spice Beach Club Bali. Pemesanan terhadap hidangan halal sekitar $91,7 \%$, hal tersebut menunjukkan potensi yang dimiliki oleh produk halal akan semakin meningkat.

\section{Saran-saran}

Adapun beberapa saran yang dapat penulis berikan dalam penerapan halal pada makanan di restoran Spice Beach Club Bali adalah sebagai berikut: 1) Untuk Penelitian Selanjutnya, agar dapat dilakukan penelitian selanjutnya yang lebih spesifik tentang penerapan halal pada makanan. 2) Untuk Spice Beach Club Bali, agar dapat dijadikan sebagai masukan dan pengetahuan tentang bagaimana menyimpan bahan makanan halal dan nonhalal dalam tempat yang sama. 


\section{Daftar Pustaka}

Achyar, Mahmud. 2015. “Indonesia Sebagai Tujuan Halal Tourism”. Tersedia pada https://achyar89.wordpress.com/2015/07/01/indonesia-sebagai-tujuan-halaltourism/ (diakses tanggal 11 April 2019 pukul 01:31 wita).

Afroniyati, Lies.2014. "Analisis Ekonomi Politik Sertifikasi Halal Oleh Majelis Ulama Indonesia". Tersedia pada https://journal.ugm.ac.id/jkap/article/view/6870 (diakses tanggal 11 April 2019 pukul 02:47 wita).

Bahruddin, Moh.2010. "Problem Sertifikasi Halal Produk Pangan Hewani". Tersedia pada http://ejournal.radenintan.ac.id/index.php/asas/article/view/440 (diakses tanggal 11 April 2019 pukul 01:43 wita).

Bartono dan Ruffino. 2005. Food Product Management di Hotel dan Restoran. Yogjakarta: Penerbit Andi.

Chairunnisyah, Sheilla. 2017. "Peran Majelis Ulama Indonesia Dalam Menerbitkan Sertifikat Halal Pada Produk Makanan Dan Kosmetika”. Tersedia pada http://jurnal.umsu.ac.id/index.php/edutech/article/view/1251 (diakses tanggal 10 April 2019 pukul 22:50 wita).

Charity, Lim, May. 2017. “Jaminan Produk Halal Di Indonesia (Halal Products Guarantee In Indonesia)". Tersedia pada http://ditjenpp.kemenkumham.go.id/jurnal/index.php/jli/article/view/26 (diakses tanggal 11 April 2019 pukul 01:39 wita).

Hari Minantyo. (2011). Dasar-dasar Pengolahan Makanan. Yogyakarta: Graha Ilmu.

Jingga, Fredy dan Limantara, Natalia. 2014. "Pembangunan Model Restaurant Management System". Tersedia pada http://journal.binus.ac.idindex.phpcomtecharticleview2348 (diakses tanggal 10 April 2019 pukul 22:30 wita).

Mujiono, Slamet. 2016. "Perlindungan Konsumen : Regulasi Bisnis". Tersedia pada https://journal.febi.uinib.ac.id/index.php/jebi/article/view/5 (diakses tanggal 10 April 2019 pukul 23:15 wita).

Rama, Ali. 2014.” Potensi Pasar Produk Halal Dunia”. Tersedia pada https://www.academia.edu/10449487/Potensi Pasar Produk Halal Dunia (diakses tanggal 11 April 2019 pukul 01:34 wita).

Rutherford, D.G., dan O'Fallon, M.J. (2010). Hotel Managment and Operations. (5th Edition). New Jersey: John Wiley and Sons, Inc.

Sakti, Muthia, dkk. 2015. "Perlindungan Konsumen Terhadap Beredarnya Makanan Yang Tidak Bersertifikat Halal". Tersedia pada https://ejournal.upnvj.ac.id/index.php/Yuridis/article/viewFile/161/133 
(diakses tanggal 11 April 2019 pukul 01:49 wita).

Salehudin, I. dan Mukhlish, B.M. 2012. "Pemasaran Halal: Konsep, Implikasi dan Temuan di Lapangan". Tersedia pada https://www.academia.edu/4060597/Pemasaran Halal Konsep Implikasi dan Temuan di Lapangan (diakses tanggal 11 April 2019 pukul 01:42 wita).

Salusu, J. 2006. Pengambilan Keputusan Strategic Untuk Organisasi Publik dan Organisasi Non Profit. Jakarta: Grasindo Gramedia Widia Sarana Indonesia

Santoso, Imam. 2016. "Peran Kualitas Produk dan Layanan, Harga dan Atmosfer Rumah Makan Cepat Saji terhadap Keputusan Pembelian dan

Kepuasan Konsumen". Tersedia pada https://www.neliti.com/id/publications/115805/peran-kualitas-produk-dan-layanan-hargadan-atmosfer-rumah-makan-cepat-saii-terh (diakses tanggal 11 April 2019 pukul 01:37 wita).

Saparinto, C. dan Hidayati. 2010. Bahan Tambahan Pangan. Yogyakarta. Kanisius.

Soekresno. 2001. Manajemen Food \& Beverage Service Hotel. Jakarta: PT.Gramedia Pustaka Utama.

Sucipto, Cecep Dani. 2015. Keamanan Pangan Untuk Kesehatan Manusia. Yogyakarta: Gosyen Publishing.

Syafrida.2016. "Sertifikat Halal Pada Produk Makanan Dan Minuman Memberi Perlindungan Dan Kepastian Hukum Hak-Hak Konsumen Muslim". Tersedia pada https://media.neliti.com/media/publications/135011-ID-sertifikat-halal-pada-produkmakanan-dan.pdf (diakses tanggal 11 April 2019 pukul 02:35 wita).

Triasih, Dharu, dkk. 2016. “ Kajian Tentang Perlindungan Hukum bagi Konsumen Terhadap Produk Makanan Bersertifikat Halal”. Tersedia pada http://journals.usm.ac.id/index.php/jdsb/article/download/571/382 (diakses tanggal 11 April 2019 pukul 01:46 wita).

Walker, Bruce J. 2004. Marketing 13th Edition. New York: McGraw-Hill Companies, Inc.

Winartha, I Made, 2006. Metodologi Penelitian Sosial Ekonomi. Andi Offset, Yogyakarta.

www.google.com. 2019. "Peta Spice Beach Club". Tersedia pada https://www.google.com/maps/place/Spice+Beach+Club+Bali/@8.3461658,114.8619909,10z/data=!4m5!3m4!1s0x0:0x5888394ed5070ae0!8m2!3d$\underline{8.164021 ! 4 \mathrm{~d} 115.020793}$

Zulaekah, Siti dan Kusumawati, Yuli. 2005. "Halal Dan Haram Makanan Dalam Islam". Tersedia pada https://publikasiilmiah.ums.ac.id/xmlui/handle/11617/856 (diakses tanggal 11 April 2019 pukul 01:21 wita). 